Т. Б. Бадмажапова, Ю. А. Балочин, Р. И. Гомбоев, Б. Б. Дамдинов, Ш. Б. Цыдыпов. Фононные кристаллы: управление акустическими волнами

УДК 534.2

DOI 10.18101/2306-2363-2019-4-55-60

\title{
ФОНОННЫЕ КРИСТАЛЛЫ: УПРАВЛЕНИЕ АКУСТИЧЕСКИМИ ВОЛНАМИ
}

(C) Бадмажапова Т. Б.

студент, Бурятский государственный университет им. Д. Банзарова 670000, Улан-Удэ, ул. Смолина, 24а

E-mail: badmazhapova97@inbox.ru

(С) Балошин Ю. А.

доктор физико-математических наук, профессор,

Санкт-Петербургский национальный исследовательский университет информационных технологий, механики и оптики

197101, Санкт-Петербург, Кронверкский пр., 49

E-mail: baloshin1940@mail.ru

(C) Гомбоев Р. И.

аспирант,

Сибирский федеральный университет

660041, Красноярск, пр. Свободный, 79

E-mail: dababa@mail.ru

(С) Дамдинов Б. Б.

доктор физико-математических наук, профессор,

Сибирский федеральный университет

660041, Красноярск, пр. Свободный, 79

Бурятский государственный университет им. Д. Банзарова

670000, Улан-Удэ, ул. Смолина, 24а

E-mail: bdamdinov@sfu-kras.ru

\section{(С) Цыдыпов Ш. Б.}

доктор технических наук, доцент,

Бурятский государственный университет им. Д. Банзарова

670000, Улан-Удэ, ул. Смолина, 24a

E-mail: shulun@bsu.ru

Рассмотрены современные исследования в области акустических метаматериалов, в частности, фононных кристаллов. Проведено предварительное численное моделирование фононного кристалла с периодически изменяющимся сечением. Показано, что при определённых условиях фононный кристалл приобретает свойства акустического фильтра. Полученные результаты можно рассматривать как научный задел в этом направлении исследований и рассматривать, прежде всего, с точки зрения задач современной акустики в разработке новых акустических волноводов, звукоизоляторов, фильтров и акустических метаматериалов. Подробный анализ может быть проделан для фононных кристаллов любой геометрии (одномерных, 2D и 3D) в разных частотных областях акустического спектра.

Ключевые слова: фононный кристалл; моделирование; акустическая волна; контроль; фильтр; метаматериал; жидкость. 
Для цитирования:

Бадмажапова Т. Б., Балошин Ю. А., Гомбоев Р. И., Дамдинов Б. Б., Цыдыпов Ш. Б. Фононные кристаллы: управление акустическими волнами // Вестник Бурятского государственного университета. Химия. Физика. 2019. Вып 4. С. 55-60.

Концепция фононных кристаллов появилась в 1990-х годах [1-3], являясь во многом продолжением работ по фотонным кристаллам $[4,5]$. Фононные кристаллы обладают различными частотными характеристиками, например, такими, как возможность возникновения запрещённых частотных зон. Особую группу занимают метаматериалы с гиперболической дисперсией $[6,7]$. Наличие сильной оптической анизотропии приводит к тому, что распространение волн в ортогональных направлениях метаматериала имеет разный характер обусловленный разными знаками эпсилонов для этих направлений. Гиперболические метаматериалы обладают двумя очень важными, уникальными свойствами: 1) они поддерживают распространение электромагнитных волн с большим значением волнового вектора; 2) они обладают повышенной плотностью фотонных состояний, что позволяет контролировать процессы электромагнитной природы в непосредственной близости от метаматериала. По аналогии с электродинамикой в акустике наличие повышенной плотности фононных состояний может существенно модифицировать силовой и энергетический ландшафт поверхности акустического метаматериала и тем самым влиять на процессы физической адсорбции, смачиваемости поверхности жидкостью и т.д., тех процессов, которые регулируются взаимодействиями Ван дер Ваальса и Казимира. Контроль и управление акустическими (упругими) волнами является на сегодняшний день фундаментальной проблемой со многими потенциальными приложениями, особенно в области информационных и коммуникационных технологий (например, новые акустические волноводы, звукоизоляторы, фильтры), которые могут быть использованы для эффективной и широкополосной звукоизоляции. Такие задачи на современном этапе исследований (теоретических, модельных и экспериментальных) решаются с помощью акустических метаматериалов и фононных кристаллов.

\section{Фононные кристаллы}

Мы остановимся здесь на фононных кристаллах, своего рода разновидностью метаматериалов. Фононные кристаллы представляют собой гетерогенные упругие среды (рис. 1), состоящие из периодического массива включений в масштабе длины волны с акустическим импедансом, встроенных в матрицу с импедансом (для метаматериалов период включений много меньше длины волны).

В современных исследованиях определяют три класса фононных кристаллов, которые отличаются друг от друга физической природой включений и матрицами: твердое-твердое, жидкое-жидкое и смешанное: жидкое-твёрдое или твёрдоежидкое. Российский физик Ю. Бобровницкий [9] опубликовал хороший обзор по акустическим метаматериалам в качестве поглотителей звука. Показано, что большая часть публикаций с точки зрения эффективности поглощения сводится к реализации одного из двух идеальных поглотителей: черного тела Кирхгофа и оптимального поглотителя. Наиболее перспективными представляются поглотители из акустических метаматериалов, реализующие идеальные тела наилучшим 
Т. Б. Бадмажапова, Ю. А. Балочин, Р. И. Гомбоев, Б. Б. Дамдинов, Ш. Б. Цыдыпов. Фононные кристаллы: управление акустическими волнами

образом, для изготовления которых необходимы развитые аддитивные технологии.
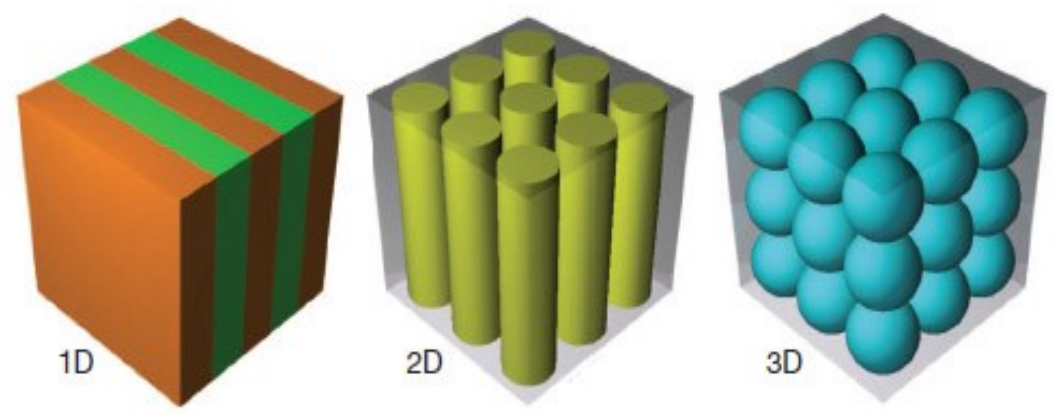

Рис. 1. Одно-, дву-и трехмерные периодические структуры с чередующимися упругими свойствами являются основой для фононики [8]

В однородном материале закон дисперсии примерно линеен - длина волны примерно пропорциональна периоду колебания; коэффициент пропорциональности (скорость волны) практически постоянен для самых разных длин волн. В фононном кристалле эта зависимость становится сильно нелинейной, а значит, скорость звуковой волны резко зависит от длины волны. Более того, в спектре фононов появляется «запрещенная зона» частот. Если попытаться в кристалл запустить звуковую волну с частотой, попадающей в эту зону, то она попросту не сможет в кристалл пролезть: частично отразится, а частично затухнет на глубине в несколько длин волн. Таким образом, кристалл не только меняет закон распространения звука, но и намертво заглушает его в определенном диапазоне частот. Этими свойствами фононный кристалл очень напоминает обычный кристалл с его разрешенными и запрещенными зонами для электронов проводимости, а также фотонный кристалл - периодическую структуру из прозрачных слоев, которая блокирует свет в некотором диапазоне частот. Акустический метаматериал - это тоже периодическая структура из материалов с разными упругими свойствами, но только шаг чередования здесь намного меньше длины волны. Изза этого звуковая волна распространяется так, словно она и не чувствует уже отдельных границ раздела, а вместо этого ощущает некую однородную «метасреду» с необычными упругими свойствами, которые можно настраивать. Отражения волна уже не испытывает, зато она может изгибаться, отклоняться или просто обладать странным законом дисперсии.

Основным направлением наших исследований является выявление особенностей распространения акустических сигналов в фононных кристаллах с изменяющимися во времени свойствами его структуры. В этом случае фононный кристалл может приобрести свойства фазового фильтра. 


\section{Результаты и обсуждение}

В качестве первого шага нами была рассмотрена задача на примере одномерного фононного кристалла в виде акустического волновода с периодически изменяемым сечением [10], заполненным коллоидным раствором ферромагнитных частиц (частиц магнитного железняка - магнетита) в воде (вариант структуры твёрдое-жидкое). Данный раствор рассматривается как идеальная жидкость с контролируемыми вязкоупругими свойствами (вязкость сдвиговая и структура $[11,12])$. Было проведено модельное исследование характеристик фононного кристалла, в котором акустические характеристики элементов его структуры меняются внешним магнитным полем с частотой, сопоставимой с частотой распространяющегося звука. В частности была рассчитана амплитудно-частотная характеристика (АЧХ) давления в среде фононного кристалла, как функция частоты магнитного поля для двух выбранных значений модуля всестороннего сжатия $\mathrm{K}_{1}=2$ ГПа и $\mathrm{K}_{2}=2,2$ ГПа. Показано, что на частотах от 15 до 20 кГц наблюдается провал в АЧХ (hис.2). Для области частот от 20 кГц до 22 кГц для данного фононного кристалла при выбранных параметрах возможна перестройка пропускания через него акустического сигнала.

Проведен анализ дисперсионных характеристик такого типа материалов [10]. Показано, что при определённых условиях фононный кристалл приобретает свойства фазового фильтра.

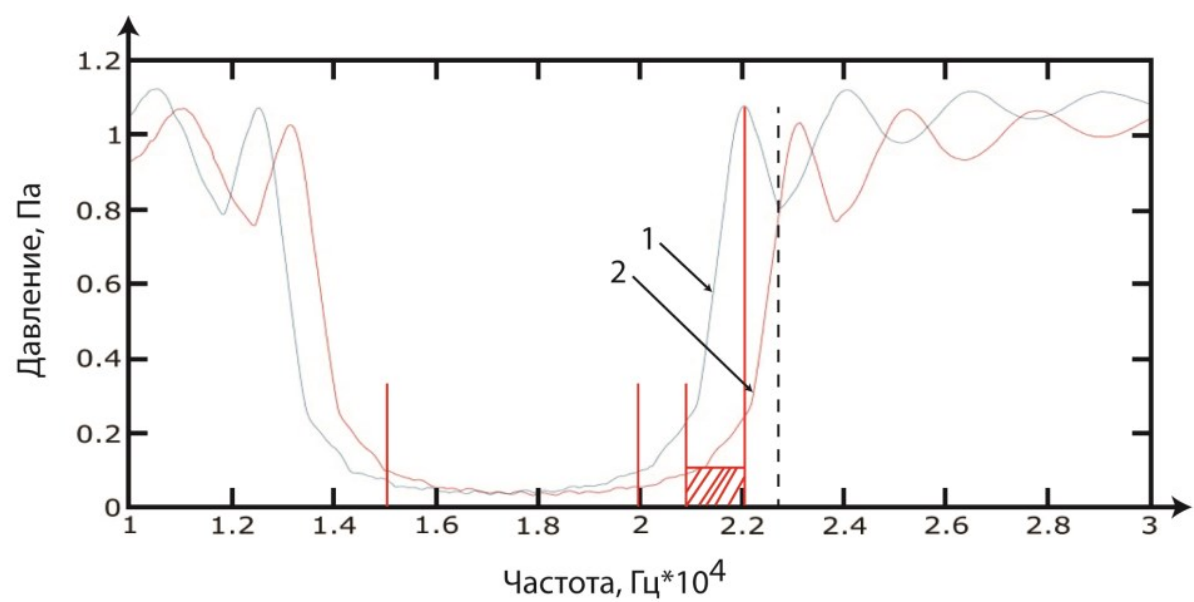

Рис. 2. Амплитудно-частотная характеристика давления в среде фононного кристалла, как функция частоты магнитного поля для сред с различной сжимаемостью $1-\mathrm{K}_{1}=2$

гПа и $2-\mathrm{K}_{2}=2,2$ ГПа

\section{Заключение}

Таким образом, полученные результаты можно рассматривать как научный задел в этом направлении исследований и рассматривать, прежде всего, с точки зрения задач современной акустики в разработке новых акустических волноводов, звукоизоляторов, фильтров и акустических метаматериалов. Подробный 
Т. Б. Бадмажапова, Ю. А. Балочин, Р. И. Гомбоев, Б. Б. Дамдинов, Ш. Б. Цыдыпов. Фононные кристаллы: управление акустическими волнами

анализ может быть проделан для фононных кристаллов любой геометрии (одномерных, 2D и 3D) в разных частотных областях акустического спектра.

Работа выполнена при поддержке РФФИ грант 18-02-00523

\section{Литература}

1. Yablonovitch E., Gmitter T. J. and Leunget K. M. Photonic band structure: The facecentered-cubic case employing nonspherical atoms // Phys. Rev. Lett. — 1991. — V. 67, № 17. - P. 2295-2299.

2. Kushwaha M. S. Halevi P., Dobrzynski L., Djafari-Rouhani B. Theory of acoustic band structure of periodic elastic composites // Phys. Rev. B. - 1994. - V. 49, № 4. - P. $2313-2322$

3. Богомолов В. Н., Парфеньева Л. С., Смирнов И. А. Мисиорек Х., Ежовский А. Прохождение фононов через фотонные кристаллы - среды с пространственной модуляцией акустических свойств // ФТТ. - 2002. - Т. 44, вып. 1. - С. 175-179.

4. Pendry J. B. Negative Refraction Makes a Perfect Lens // Phys. Rev. Lett. — 2000. V. 85, № 18. - P. 3966-3969.

5. Zheludev N. I., Kivshar Y. S. From metamaterials to metadevices // Nature Mater. 2012. - V. 11. - P. 917-924.

6. Tumkur T. U., Zhu G., Black P., Barnakov Yu. A. Bonner C.E. and Noginov M. A. Control of spontaneous emission in a volume of functionalized hyperbolic metamaterial // Appl. Phys. Lett. - 2011. - V. 99. - P. 151115.

7. Narimanov E. E., Li H., Barnakov Yu. A., Tumkur T. U. and Noginov M. A. Reduced reflection from roughened hyperbolic metamaterial // Optics Express. - 2013. - V. 21, № 12. - P. 14956-14961.

8. Maldovan M. Sound and heat revolutions in phononics // Nature. - 2013. - V. 503. - P. 209-217.

9. Бобровницкий Ю. И., Томилина Т. М. Поглощение звука и метаматериалы // Акустическиий журнал. - 2018. - Т. 64, № 5. - С. 517 -525.

10. Demin A., Damdinov B., Baloshin Yu. Numeric Modeling of Phononic Crystal with Time-Dependent Properties // J. Phys. Conf. Ser. - 2020 (in press).

11. Бадмаев Б. Б., Дембелова Т. С., Дамдинов Б. Б. Вязкоупругие свойства полимерных жидкостей. - Улан-Удэ: Изд-во БНЦ СО РАН, 2013. - 190 с.

12. Badmaev B. B., Budaev O. R., Dembelova T. S., Damdinov B. B. Shear elasticity of fluids at low-frequency shear influence // Ultrasonics. — 2006. - V. 44, Suppl 1. — P. 14911494.

\section{PHONONIC CRYSTALS: ACOUSTIC WAVE CONTROL}

Badmazhapova T. B.

Student

Buryat State University named by D. Banzarov

670000, Ulan-Ude, Smolina Str., 24a

E-mail: badmazhapova97@inbox.ru

Baloshin Y. A.

Doctor of Physics and Mathematics Sciences, Professor

ITMO University,

197101, Saint-Petersburg, Kronverovsky pr., 49

E-mail: baloshin1940@mail.ru 
Gomboev R. I.

Postgraduate

Siberian Federal University

660041, Krasnoyarsk, Svobodny pr., 79

E-mail: dababa@mail.ru

Damdinov B. B.

Doctor of Physics and Mathematics Sciences, Professor

Siberian Federal University

660041, Krasnoyarsk, Svobodny pr., 79

Buryat State University named by D. Banzarov

670000, Ulan-Ude, Smolina Str., 24a

E-mail: bdamdinov@sfu-kras.ru

Tsydypov Sh. B.

Doctor of Technical Sciences

Buryat State University named by D. Banzarov

670000, Ulan-Ude, Smolina Str., 24a

E-mail: shulun@bsu.ru

Modern researches in the field of acoustic metamaterials, in particular, phonon crystals, are considered. A preliminary numerical simulation of a phonon crystal with a periodically changing cross-section is carried out. It is shown that under certain conditions the phonon crystal acquires the properties of an acoustic filter. The obtained results can be considered as a scientific groundwork in this direction of research and considered, first of all, from the point of view of the problems of modern acoustics in the development of new acoustic waveguides, sound absorbers, filters and acoustic metamaterials. Detailed analysis can be done for phonon crystals of any geometry (one-dimensional, 2D and 3D) in different frequency regions of the acoustic spectrum.

Keywords: phononic crystal; numeric simulation; acoustic wave; control; filter; metamaterial; liquid. 